\title{
BMJ Open Retrospective observational study of characteristics of persons with amputations accessing International Committee of the Red Cross (ICRC) rehabilitation centres in five conflict and postconflict countries
}

\author{
Cornelia Anne Barth (D) , ${ }^{1,2}$ Andreas Wladis, ${ }^{3}$ Catherine Blake, ${ }^{1}$ \\ Prashant Bhandarkar, ${ }^{4,5}$ Sigiriya Aebischer Perone, ${ }^{6,7}$ Cliona O'Sullivan (1) ${ }^{1}$
}

To cite: Barth CA, Wladis A Blake C, et al. Retrospective observational study of characteristics of persons with amputations accessing International Committee of the Red Cross (ICRC) rehabilitation centres in five conflict and postconflict countries. BMJ Open 2021;11:e049533. doi:10.1136/ bmjopen-2021-049533

- Prepublication history for this paper is available online. To view these files, please visit the journal online (http://dx.doi. org/10.1136/bmjopen-2021049533).

Received 28 January 2021 Accepted 05 November 2021

Check for updates

(c) Author(s) (or their employer(s)) 2021. Re-use permitted under CC BY-NC. No commercial re-use. See rights and permissions. Published by BMJ.

For numbered affiliations see end of article.

Correspondence to Dr Cornelia Anne Barth; cornelia.barth@unisante.ch

\section{ABSTRACT}

Objectives Limb amputation incidence is particularly high in fragile contexts due to conflict, accidents and poorly managed diabetes. The study aim was to analyse (1) demographic and amputation characteristics of persons with any type of acquired amputation (PwA) and (2) time between amputation and first access to rehabilitation in five conflict and postconflict countries.

Design A retrospective, observational study analysing differences in demographic and clinical factors and time to access rehabilitation between users with traumatic and non-traumatic amputations.

Setting Five countries with the highest numbers of PwA in the global International Committee of the Red Cross database (Afghanistan, Cambodia, Iraq, Myanmar, Sudan). Cleaned and merged data from 2009 to 2018 were aggregated by sex; age at amputation and registration; cause, combination and anatomical level of amputation(s); living environment.

Participants All PwA newly attending rehabilitation. Results Data for 28446 individuals were included (4 $329(15.2 \%)$ female). Most were traumatic amputations (73.4\%, 20890$)$; of these, 48.6\% (13 801) were conflict related. Average age at traumatic amputation for men and women was 26.9 and 24.1 years, respectively; for non-traumatic amputation it was 49.1 years and 45.9 years, respectively. Sex differences in age were statistically significant for traumatic and non-traumatic causes $(p<0.001, p=0.003)$. Delay between amputation and rehabilitation was on average 8.2 years for those with traumatic amputation, significantly higher than an average 3 years for those with non-traumatic amputation $(\mathrm{p}<0.001)$

Conclusions Young age for traumatic and non-traumatic amputations indicates the devastating impact of war and fragile health systems on a society. Long delays between amputation and rehabilitation reveal the mismatch of needs and resources. For rehabilitation service providers in fragile settings, it is an enormous task to manage the diversity of PwA of various causes, age, sex and additional conditions. Improved collaboration between
Strengths and limitations of this study

To our knowledge, this is the first large multicountry study on a highly vulnerable and neglected group of persons with amputations seeking rehabilitation in conflict and postconflict contexts.

- Data originate from exceptionally challenging and diverse settings where providing rehabilitation and collecting data is complex and constantly challenged by the volatility of the environment.

- Limitations include that data are derived from International Committee of the Red Cross supported structures only and cannot make statements on overall population or on persons not attending services.

primary healthcare, surgical and rehabilitation services, a prioritisation of rehabilitation and increased resource provision are recommended to ensure adequate access to comprehensive rehabilitation care for PwA.

\section{INTRODUCTION}

Limb amputation is a life-changing event. Global incidence studies reveal a substantial lack of data from fragile contexts such as conflict-affected or low-income and middleincome countries (LMICs), but research has shown that amputation incidence is higher in populations with low economic and educational status. This results in limited access to healthcare, even in high-income countries (HIC).${ }^{1-3}$ People in fragile contexts are particularly at risk of amputation and many of them will have to cope without prosthetic care. ${ }^{45}$ Appropriate rehabilitation and assistive technology (AT) have the potential to greatly diminish disability and allow the person to lead an independent, functional 
life. ${ }^{67}$ It requires the availability of comprehensive, costly and lifelong services, which is an enormous challenge in such environments. Rehabilitation services should span from early physiotherapy to prosthetic fitting, psychosocial support and social reintegration measures. A lower extremity amputation (LEA) requires prosthetic renewal every 3 years, for children every 6 months. ${ }^{8}$

The World Health Assembly's 2018 resolution on improving access to AT and the 2021 resolution on the highest attainable standard of health for persons with disabilities indicate the many shortcomings and the need for increased recognition in this field. ${ }^{59}$

Access to appropriate rehabilitation and AT is a human right enshrined in the Convention on the Rights of Persons with Disabilities. This recognition has resulted in publications discussing implications, implementation and sobering reality-checks in numerous LMICs. ${ }^{10-15}$

Alarming needs and low supply are a well-known reality for global actors playing a key role in advocating for and providing rehabilitation in fragile settings including the International Committee of the Red Cross (ICRC), Humanity and Inclusion and the WHO. Guidelines, training resources and advocacy papers by such actors, often issued collectively, are specifically pointing out the importance and interdependence of early rehabilitation, AT and rehabilitation across the continuum of care. ${ }^{16-21}$

As such initiatives address knowledge gaps in this neglected field, their global implementation lags behind, even more so in countries of prolonged conflict or postconflict with fragile health systems and a deprioritisation of rehabilitation services. As a consequence, there remains a lack of scientific papers on which to base further guideline development and research. This starts with affected populations in the countries themselves who remain largely unknown, contrary to the well-studied veterans from HIC who sustained conflict-related amputations abroad. ${ }^{22-24}$ Complex traumatic amputations and their sequalae in conflict-affected and mine-affected areas are known to be a huge challenge. ${ }^{4526}$ Adding to this, and with profound consequences, is the increasing global burden of type 2 diabetes mellitus (T2D). ${ }^{27}$

Overstretched health systems, particularly in LMICs, lacking access to basic diabetic care and high rates of undiagnosed T2D increase the risk and incidence of amputations. ${ }^{28}$ Road traffic (RTA) and other accidents are an additional problem in countries with limited traffic and occupational safety standards. ${ }^{29}$

Persons with amputations (PwA) constitute the biggest cohort of users accessing rehabilitation services supported by the ICRC in conflict and postconflict states. ${ }^{30}$ Assisting conflict affected populations is at the centre of the ICRC's humanitarian mission and serving mine victims with limb loss is a core activity since the launch of its physical rehabilitation programme in $1979 .^{3132}$

Currently, the ICRC supports 152 rehabilitation structures in 35 countries offering multidisciplinary rehabilitation services for persons with physical disabilities and capacity building for rehabilitation workforce. With this support, 62172 persons worldwide were fitted with prostheses in 2019. ${ }^{31}$ There is very little information on the characteristics of PwA accessing rehabilitation in fragile contexts.

The overall aim of this study was to analyse characteristics of PwA accessing rehabilitation services in five ICRC contexts in 2009-2018 to better understand their healthcare needs and deduce implications for service provision. Specific aims were to explore differences in sex and age at amputation, at registration for rehabilitation, time between amputation and registration (delay), causes and characteristics of amputations.

\section{METHODS}

\section{Design and setting}

This retrospective observational study is an analysis of aggregated data. It reflects the records of all PwA registered from 2009 to 2018 in ICRC-supported physical rehabilitation centres (PRCs) in Afghanistan ( $\mathrm{n}=7$ ), Cambodia $(\mathrm{n}=2)$, Iraq $(\mathrm{n}=1)$, Myanmar $(\mathrm{n}=5)$ and Sudan $(\mathrm{n}=2)$. Data were extracted from an ICRC-developed electronic database described in a previous study. ${ }^{30}$ The five countries representing the highest numbers of PwA attending PRCs were selected for this study, reflecting $92 \%$ of the total number of PwA in the database. Besides postconflict Cambodia, the countries represent contexts of protracted crises and are classified by the World Bank as low-income (Afghanistan, Sudan), LMIC (Cambodia, Myanmar) or upper-middle-income (Iraq). ${ }^{33}$ These differences are equally reflected in other indicators as available from open source sites by the United Nations Development Programme and the WHO. ${ }^{35} 36$

Data reflect representative user populations in the studied countries to varying degrees depending on presence of other rehabilitation providers, or data management difficulties. All PRCs were located in urban areas.

\section{Participants}

Participants include all persons with any type of acquired amputation newly attending for prosthetic fitting. Excluded were persons attending with congenital limb loss.

\section{Data collection and management}

On registration, demographic and clinical characteristics were captured as part of routine documentation. The variables retrieved from the database were: country, sex, age at registration and at amputation, living environment, cause, anatomic level and number of amputation(s). PwA's living environment was subject to local definitions of the terms urban or rural. The quantitative variables were cleaned, merged, disaggregated by sex and age and organised into variables of interest.

Figure 1 lists the causes as retrieved from the database and shows how causes were categorised into traumatic or non-traumatic. Traumatic causes were further subcategorised as non-conflict or conflict related. We examined 


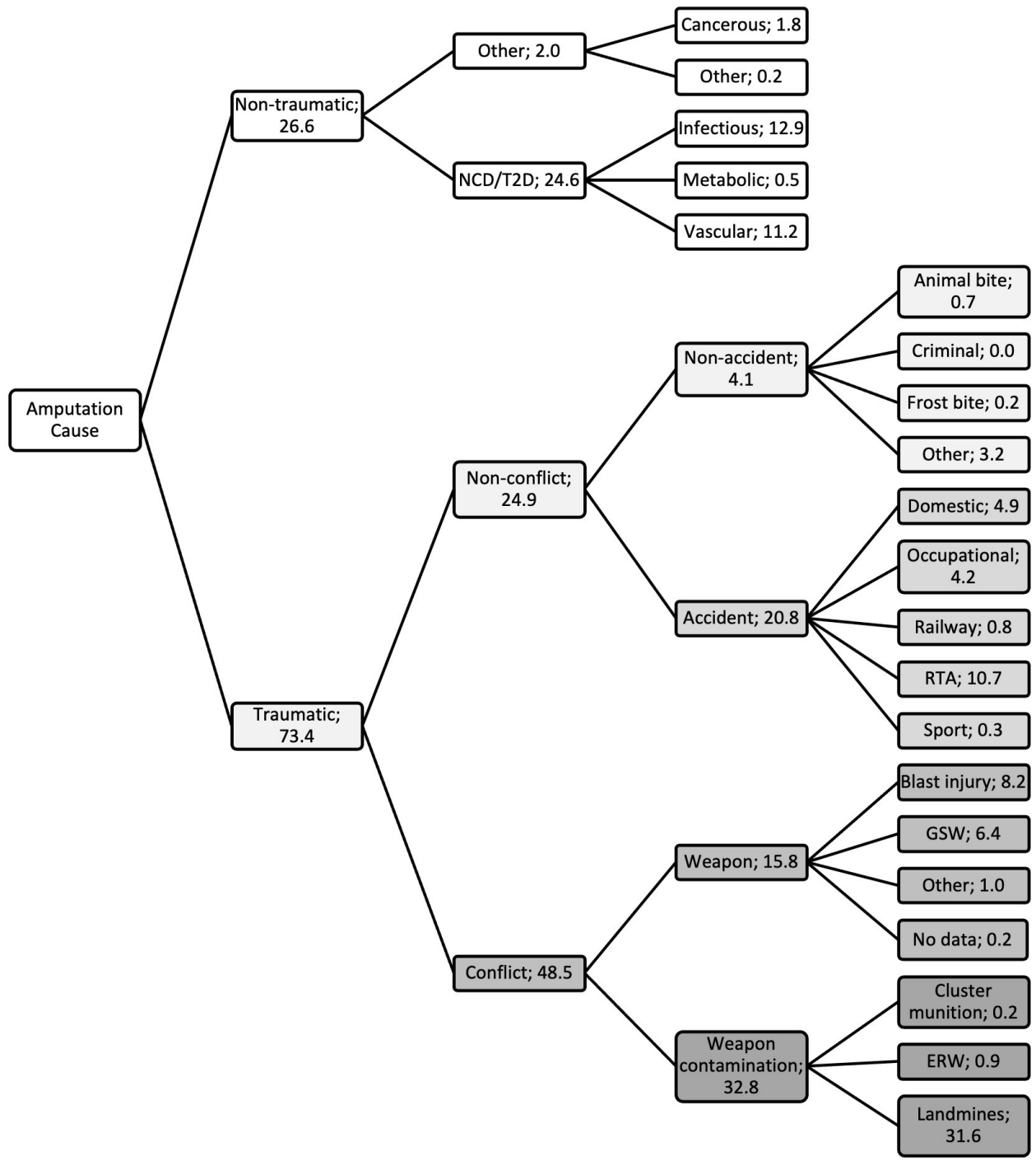

Figure 1 Classification of amputation causes with \% of total persons with amputations. All 21 variables on the right are as they appear in mandatory dropdown lists of the database. The database distinguishes between (1) traumatic and all other causes; (2) conflict-related and all other traumatic causes; (3) weapon-contamination and all other conflict-related causes; all additional categories were created based on the original 21 variables. ERW, explosive remnants of war; GSW, gunshot wound; NCD, non-communicable disease; No data, software error; RTA, road traffic accident; T2D, type 2 diabetes.

non-conflict-related traumatic causes by accidental such as RTA or non-accidental causes such as animal bite. Conflict-related causes were separated into caused by weapons or by weapon-contamination, which encompasses the presence of mines, explosive remnants of war and other sources of contamination. ${ }^{37}$

The database offered four labels for non-traumatic causes: cancerous, infectious, metabolic or vascular. For analysis, these were merged, except cancer (merged with 'other'), and considered related to non-communicable diseases (NCD), potentially T2D.

For amputation characteristics, male and female PwA were counted by combinations of LEA and upper extremity amputations (UEA) and by non-traumatic versus traumatic causes. We distinguished six levels of UEA and six levels of LEA counting number of amputations (and not persons) per level.

\section{Data analysis}

The delay between amputation and registration to rehabilitation was calculated by subtracting the self-reported amputation date from the registration date as noted on the user file.

Age at registration was grouped into young child: under 5; child: 5-17; young adult: 18-34; adult: 35-59; older adult: over 60. Besides 'living environment' all selected variables were mandatory for data entry. Where software issues led to missing data, these were labelled 'no data' in the tables.

Data analysis comprised descriptive statistics. The software packages used were Microsoft Office Excel 2016, R (V.3.6.1), R Studio for windows (V.1.2.5001) and SPSS (IBM SPSS Statistics for Windows, V.24.0., IBM). Categorical data were summarised as counts and percentages across rows (sex) and columns (groups). Age at the time of amputation, registration and delay intervals were presented as means with $95 \%$ 
CIs. Differences between groups were assessed using $\chi^{2}$ and Mann-Whitney $\mathrm{U}$ tests. Values of $\mathrm{p}<0.05$ were considered statistically significant.

\section{Potential bias}

Data depended on the accuracy of self-report and recording of observations and assessments by PRC staff with varying professional training and subject to interpretation, hereby presenting potential biases. Variables such as sex and age are deemed robust. Challenges exist when recording the cause of non-traumatic amputation presentations as PRCs are rarely attached to a medical service to diagnose underlying conditions.

Unless a PwA checks in with externally confirmed T2D diagnosis, PRC staff rely on findings from their own assessment. They record non-traumatic causes as predefined in the database, which does not offer T2D as a stand-alone variable, but 'infectious', 'metabolic' or 'vascular' presentations. Chronic, often unknown health conditions in the studied countries lead to such presentations defined by PRC staff as amputation cause and are most likely related to NCD/T2D. ${ }^{38-40}$ Considering the dimension and consequences of T2D prevalence we merged causes under this heading despite absence of confirmed diagnosis.

\section{Patient and public involvement}

For this retrospective study of routinely collected data, patient involvement in study design did not apply. However, consultation with key stakeholders (PRC managers and personnel and ICRC expatriate staff) was conducted regarding study design and feasibility and contextual analysis of findings. Interpretation of the data was based on these stakeholders' profound understanding of the respective contexts. The main author $\mathrm{CAB}$ presented and discussed preliminary research results in an ongoing process, online and in person during project visits where involved rehabilitation providers did and will continue to play an active role in dissemination of the findings of this research.

The methods used and findings from the study are reported in line with the guidelines for accurate and transparent health estimates reporting (GATHER). ${ }^{41}$

\section{RESULTS}

\section{Participant characteristics}

A total of 28446 individual user files were analysed with 4329 (15.2\%) female PwA. Most data relate to Afghanistan (12364 (43.5\%)), followed by Myanmar (5267 $(18.5 \%))$, Sudan $(5012(17.6 \%))$, Iraq (3491 (12.3\%)) and Cambodia (2312 (8.1\%)).

Age at time of amputation, age at registration, delay between amputation and registration

Average age for traumatic amputation was 26.9 years in male, 24.1 years in female. For non-traumatic amputation it was 49.1 years in male, 45.9 years in female PwA. Average delay was significantly shorter in the non-traumatic group with 3 years compared with 8.2 years for those with traumatic amputation, (table 1, figure 2). In all countries, delay was lowest in young children (0.0-2.5 years) and highest for males over 60 with traumatic amputations (16.6-22.5 years), except for Afghanistan (10.5 years for males aged $35-59$ and 10.3 years for those over 60 ).

\section{Distribution by sex and age of persons presenting with traumatic and non-traumatic amputations}

Table 2 shows that children under 18 attending were represented in low proportions $(3 \%-5.9 \%)$ in all countries except Afghanistan (2001 (16.2\%) of 12 364). Sudan had the highest proportion of PwA attending in ages over 60 (1317 (26.3\%) of 5012). Most men entering rehabilitation were of working age (18-59 years) ranging from $68.3 \%$ (Sudan) to $85.6 \%$ (Cambodia) of total males. Among women, the working age group (18-59 years) constituted between $58.7 \%$ (Iraq) and $71.4 \%$ (Myanmar) of total females.

The proportion of males accessing rehabilitation was higher in all age groups except children under five in Myanmar (3 (50.0\%) of 6). Even in older age groups ( $>60$ years) there was a significant male vs female majority (3477 $(80.7 \%)$ of 4309$)$ across all countries, relating to traumatic and non-traumatic causes. The majority of users with non-traumatic amputation were aged under 60 years, $3373(61.5 \%)$ of 5481 male and $1418(68.3 \%)$ of 2075 female PwA.

\section{Distribution of amputation causes by categories and in detail,} by country

Figure 1 illustrates how the registered causes of amputation were categorised. Most amputations were of traumatic origin, 20890 (73.4\%) of 28466 (table 3).

Among all men, 18636 (77.3\%) of 24117 had traumatic amputations. Among all women, $2254(52.1 \%)$ of 4329 had traumatic amputation.

Sudan had the highest proportion of non-traumatic amputations, 3007 (60.0\%) of 5012, outnumbering traumatic amputations across both sexes and had an overall higher female representation of 1093 (21.8\%) of 5012 compared with the remaining countries.

Despite the high numbers of conflict-related amputation in the overall cohort, 1885 (43.5\%) of 4329 females and $5114(21.2 \%)$ of 24117 males presented with a likely T2D related amputation.

One-third (9319 (32.8\%) of 28 466) of the overall cohort attended with amputation caused by weapon contamination. RTA constituted $3044(10.7 \%)$ of all amputation causes. Blast injury caused $2319(8.2 \%)$ and gunshot wound (GSW) 1834 (6.4\%) of all amputations.

More than half of all men presented with conflictrelated traumatic amputations, $12691(52.7 \%)$ of 24 117, landmines alone constituted $8571(35.3 \%)$ of all males' amputations. Within women, traumatic amputations were evenly distributed between conflict and nonconflict related (1110 (25.7\%) and $1144(26.4 \%)$ of 4329 , respectively). Landmines caused 483 (11.2\%), RTA 396 


\section{1) 同 . mo}

กิ

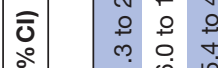

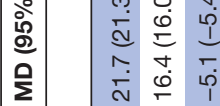

कo

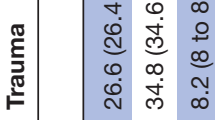

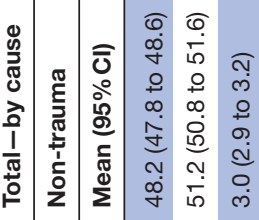

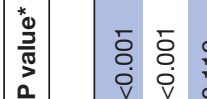

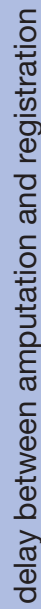

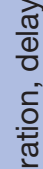

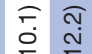

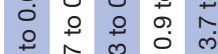

m.

0

ᄃิ

年

อ d

:
ब.

i.

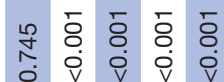

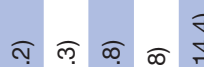
广் र

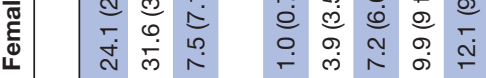
c 突

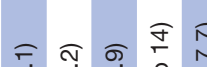

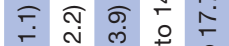
웅 웅 궁

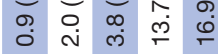

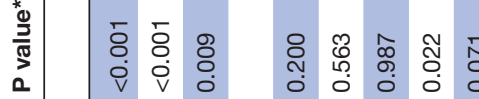

क. बढ
ㅇ ल

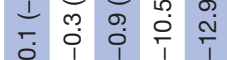

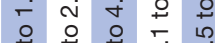

สู่ बำ สุ

요앙

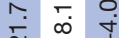

$\frac{10}{2}$ क

Nָ

क

ปั

우

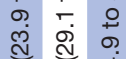

व

웡

कิ

จ $\widehat{0}$ ब

5 의 0

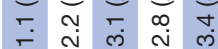

वे

웅 운

过势

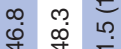

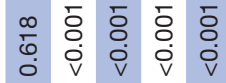

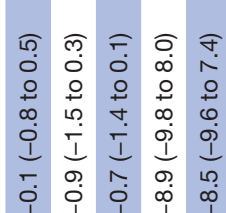

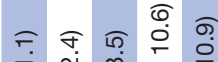

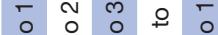

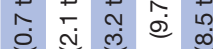

वे

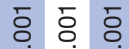
i $v$ i

कํ. $\stackrel{5}{\leftarrow} 0$ 운 ले क् สิ वं भु 웅ㅇㅇ 离 尚 क.

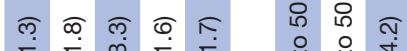
웅ㅇㅇㅇㅇㅜ ก 0 ) 0 a e 은

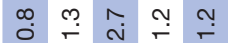

일

党

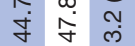

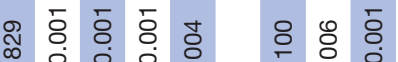
苟 ㄷ.

$\frac{-\pi}{\frac{0}{2}}$

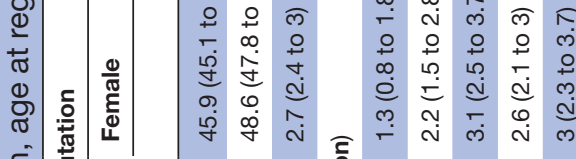

ธธธ ธㅎํㅇ

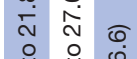

$\begin{array}{lll}\circ & 0 & \oplus \\ \forall & 0 & 0\end{array}$

คे

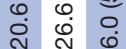

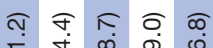

$\begin{array}{lllll} & & 0 & 0 & 0 \\ 0 & 0 & 0 & 0 & 0 \\ 0 & & 0 & 0 & 0 \\ 0\end{array}$

(․

ल

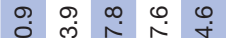

लें

요

艾

$\infty$ 过

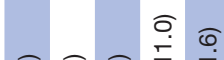

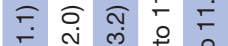

다일

잉

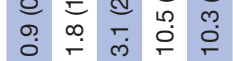

के

ले

लू ช่

m.

वิ

ले

बे $\widehat{\varphi}$

बi

우 우 우

กิ

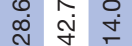

कิ

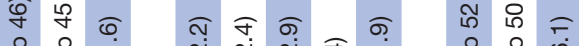

$+\frac{1}{2}+\frac{1}{0}$

ه্

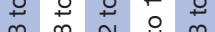

e $\dot{e}=0$

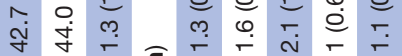

$+\frac{1}{2}$

ले 守

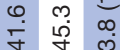

N

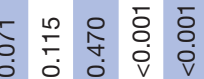

후웅

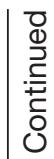

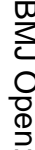

สิ

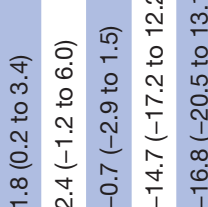

ब.

$\stackrel{0}{i}$

$\begin{array}{llll}0 & 0 & 0 & 0 \\ 0 & 0 & 0 & 0 \\ 0 & 0 & 0 & 0\end{array}$

क्ष

芒

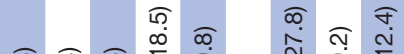

गิ

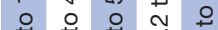

0 ᄃ m.

อ

党

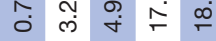

ì

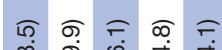

กิ

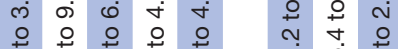

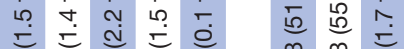

$\sum \cos ^{2}$

虫

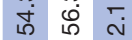

苍

๙ิ $\overline{0} \overline{0}$

$\widehat{0} \widehat{\infty}$

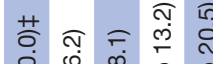

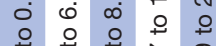

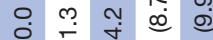

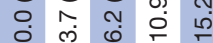

N

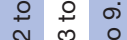

సูป

崩

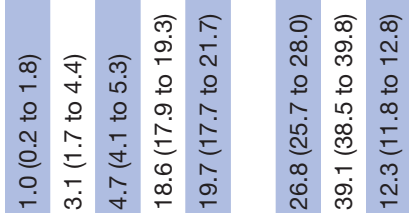

量

응

$\frac{1}{0+2}$

。

$\vec{\omega}$

을

$\frac{1}{\mathbb{0}}$

足

官

胥

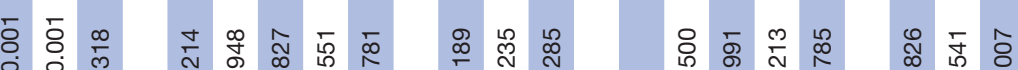
ใ่ ஓं

든

苟

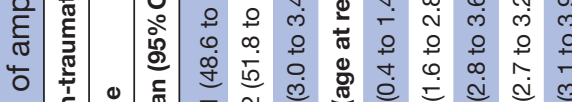

Q

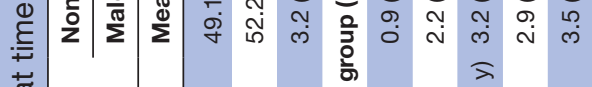

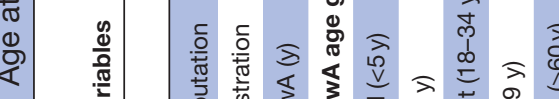

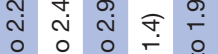

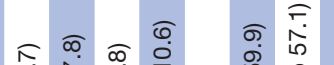

$\infty$ iे

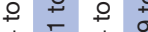

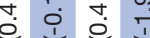

0 व

$\infty$ 앙

a

ณึ

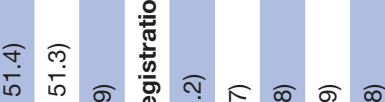

in

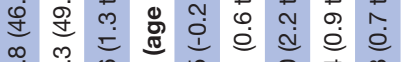

蚝

ब)

बi

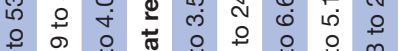

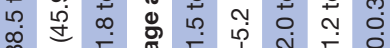

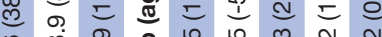

守

สิ $\widehat{0}$

in

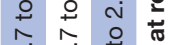

它

ㄱำ

in

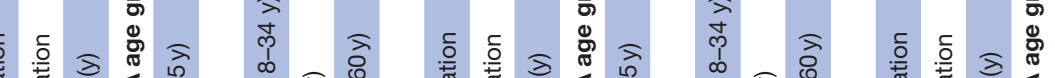

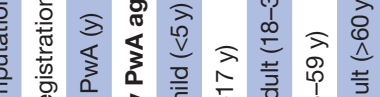

을

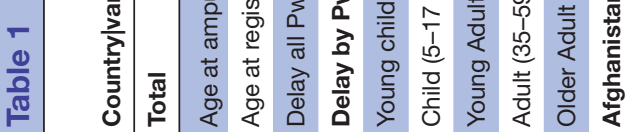

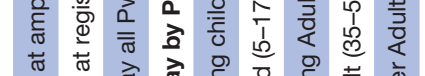

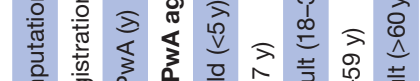

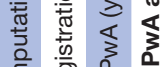

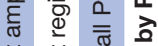

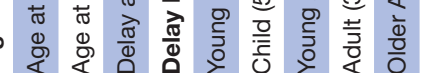

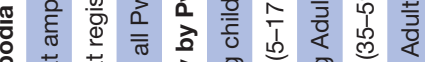

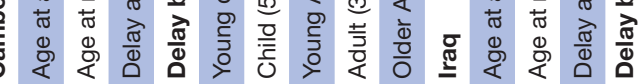

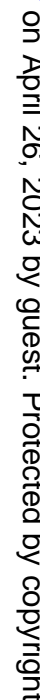




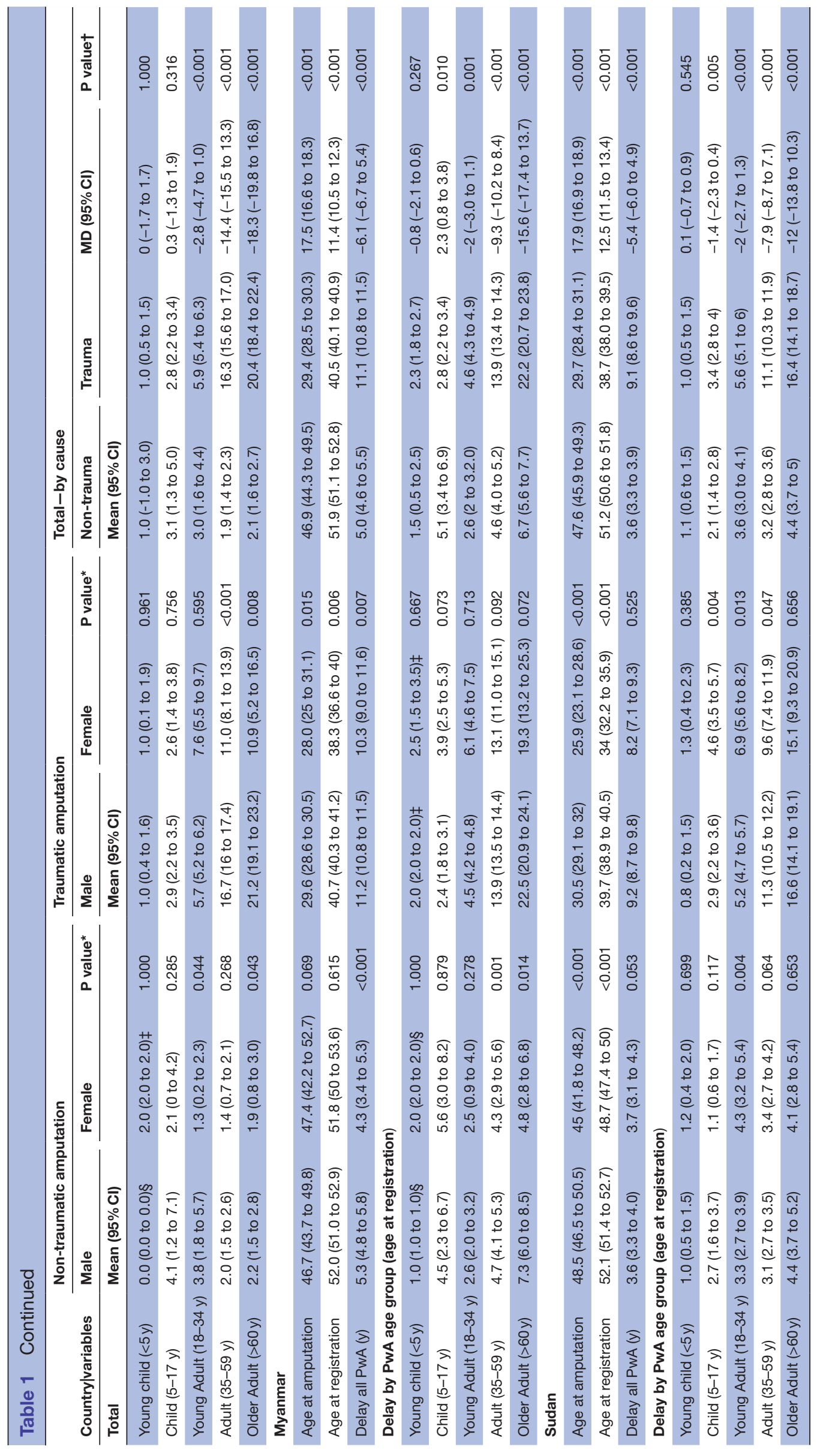



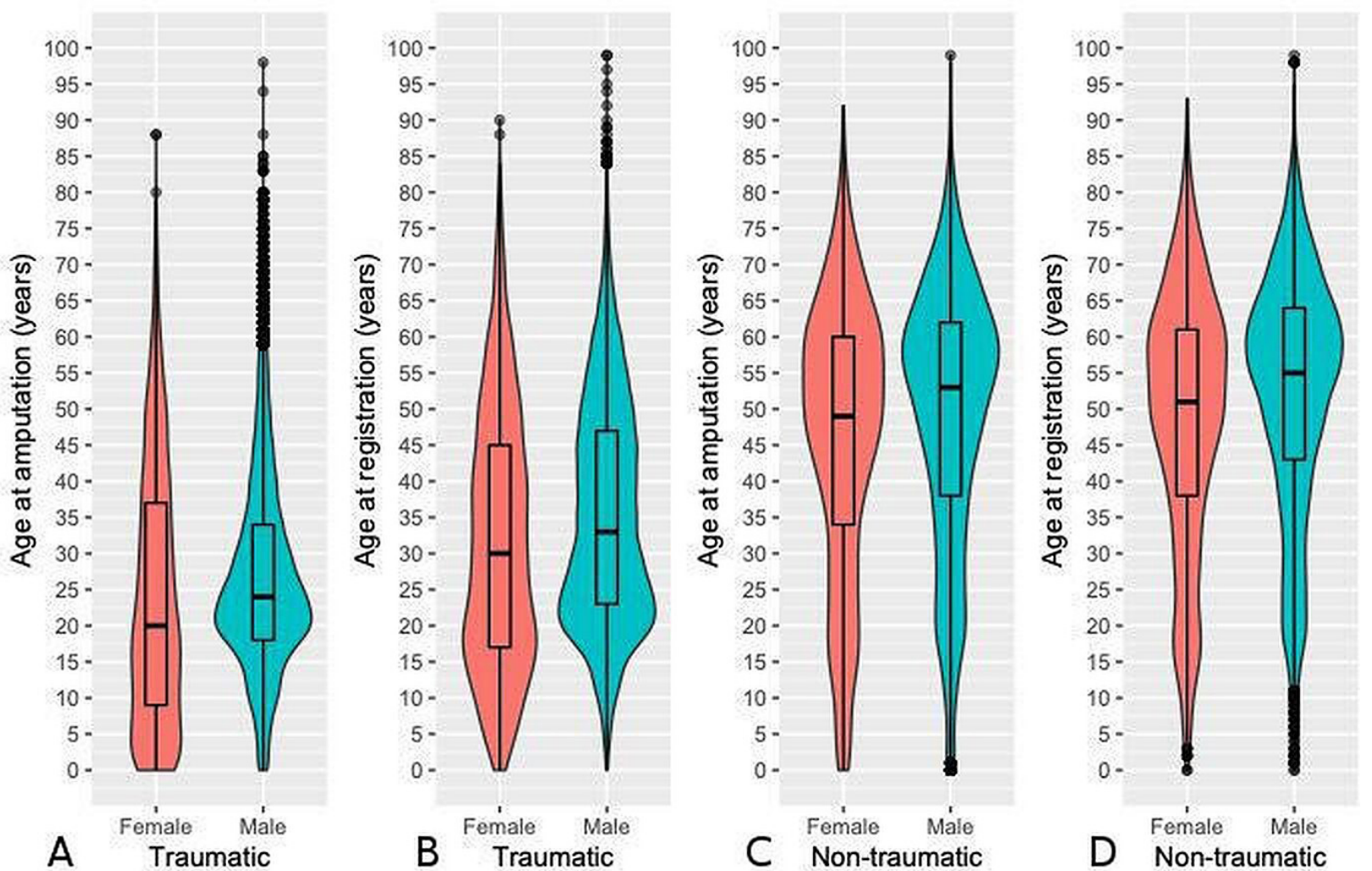

Figure 2 Age patterns of male and female persons with traumatic and non-traumatic amputation. Violin plots showing age of all male and female persons with amputations (PwA) of (A) traumatic cause at time of amputation, (B) at time of registration, age of male and female PwA of (C) non-traumatic cause at time of amputation, (D) at time of registration.

$(9.1 \%)$ and domestic accidents $369(8.5 \%)$ of all females' amputations.

Proportions of men compared with women were significantly higher in most traumatic causes. This was even more pronounced in conflict-related causes and highest for landmines, 8517 (94.6\%) of 9000. In Myanmar, weapon-contamination caused $2200(41.8 \%)$ of 5267 amputations, in Afghanistan 5147 (41.6\%) of 12 364, in Iraq $714(20.5 \%)$ of 3491, in Sudan 57 (1.1\%) of 5012 and in postconflict Cambodia 1201 (51.9\%) of 2312.

\section{Amputation characteristics: combinations and levels of amputation}

Table 4 illustrates amputation characteristics by combinations and levels. Multiple amputations were present in 2014 (8.4\%) of 24117 men and 337 (7.8\%) of 4329 women. Double LEA was the most common combination occurring in 1575 (6.5\%) men and 293 (6.8\%) women and more likely in persons with traumatic amputations (1566 $(7.5 \%)$ of 20890$)$ compared with those with non-traumatic amputations (302 (4.0\%) of 7556). In total, 30943 amputations were registered, of which 15399 (49.8\%) were transtibial. Of all non-traumatic amputations, 7680 (98.0\% of 7835$)$ were LEA, the majority transtibial $(5008(63.9 \%))$, whereas $2613(12.0 \%$ of 19182$)$ of all traumatic amputations occurred in the upper extremity.

\section{Living environment}

Most PwA reportedly came from rural environment (17 202 (60.5\%) of 28 446; 1996 (7\%) unspecified). There was a significantly higher proportion of women (1742 $(18.8 \%)$ of 9248$)$ in the urban compared with the rural population, (2308 (13.4\%) of 17 202; $\mathrm{p}<0.01)$.

\section{DISCUSSION}

Traumatic amputation at young adult age has devastating effects on a person's private and professional perspectives. A worrying finding in this study was the delay between amputation and beginning rehabilitation, particularly for those with traumatic amputation. Ideally, prosthetic fitting happens right after wound-healing. Any delay will increase functional limitations and the potential of complications. ${ }^{42}$ Consequently, duration, costs and complexity of rehabilitation will rise, including prosthetic adjustments. In cases of irreversible limitations PwA may no longer qualify for fitting. ${ }^{8}$ The studied countries are marked either by protracted crisis with recurring flares of acute fighting or postconflict with weak economy and fragile health systems. ${ }^{33}$ These factors result in high numbers of PwA, who face access difficulties to rehabilitation aggravated by compromised infrastructure and security, lack of means or awareness, and critical scarcity or overload of existing rehabilitation workforce and services. ${ }^{4344}$ 


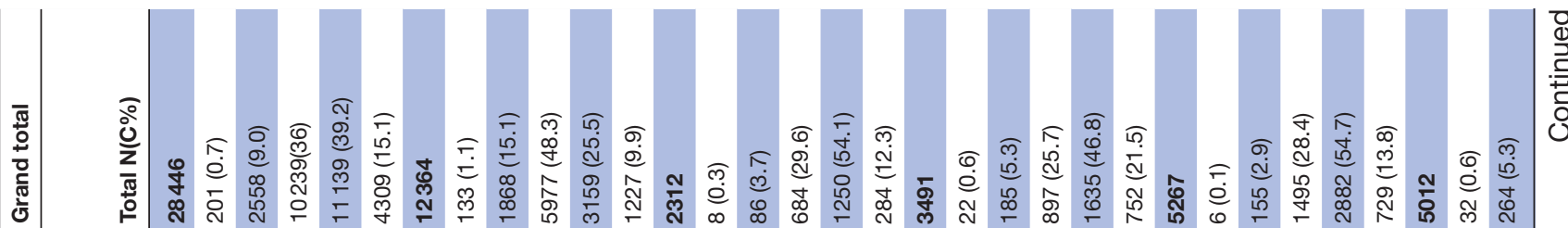

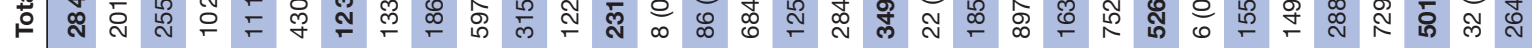

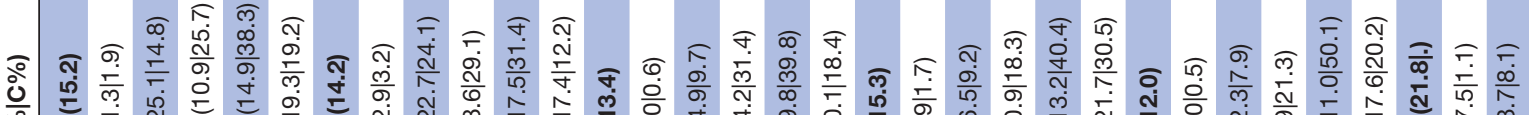

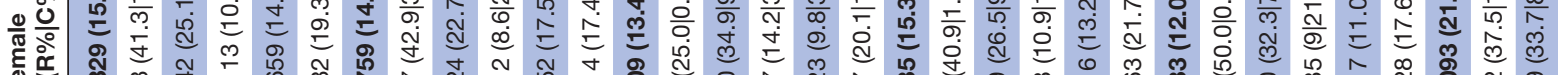

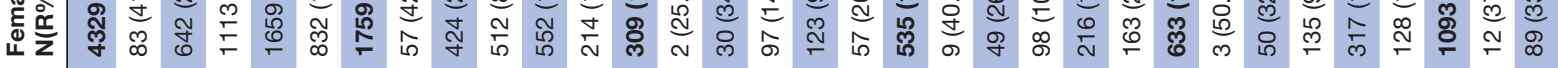

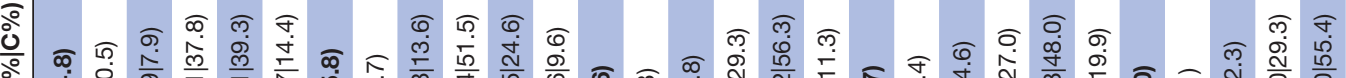

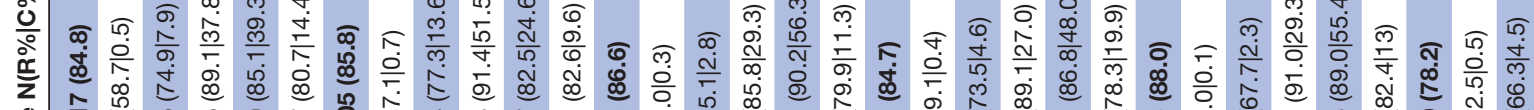

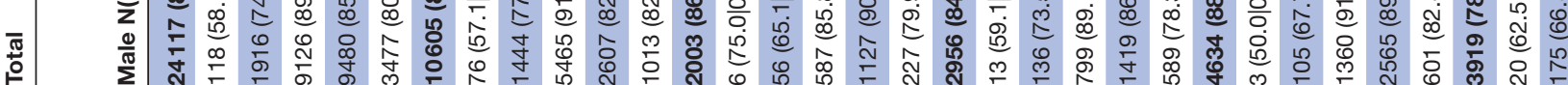

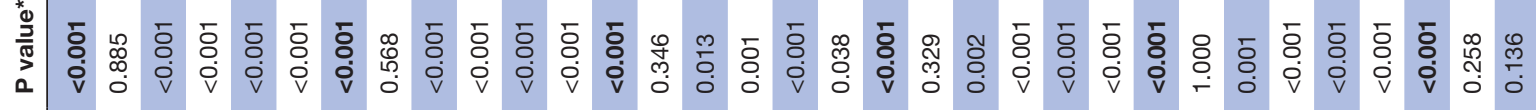

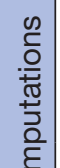

茜

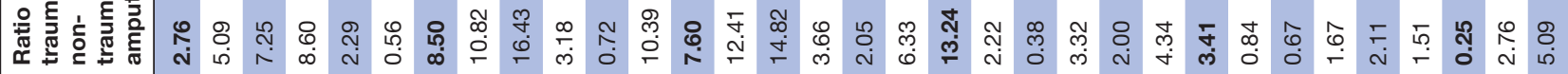

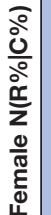

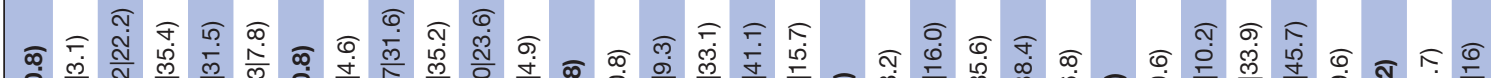

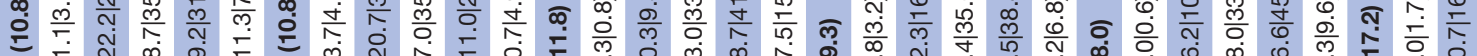

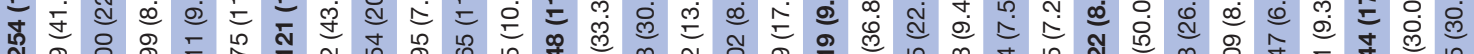

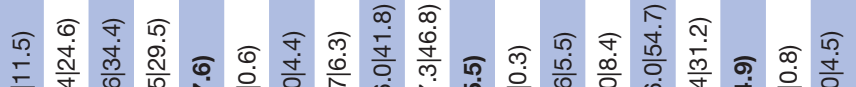

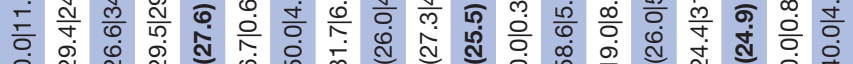

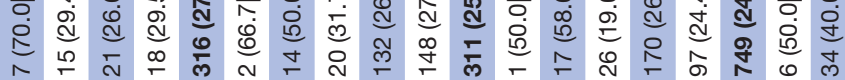

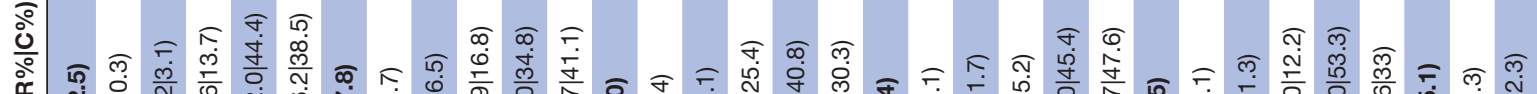

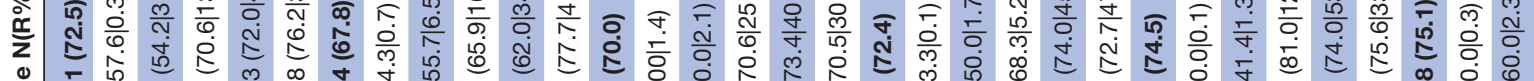

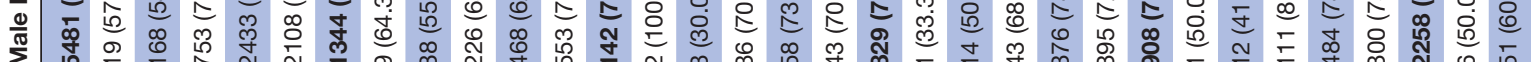

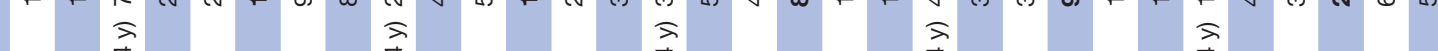

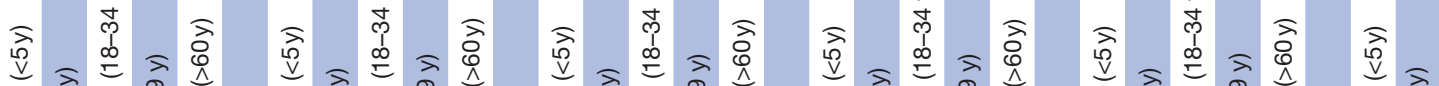

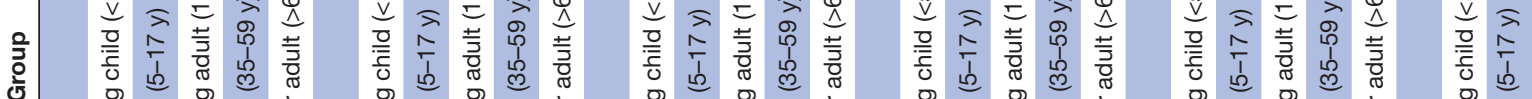

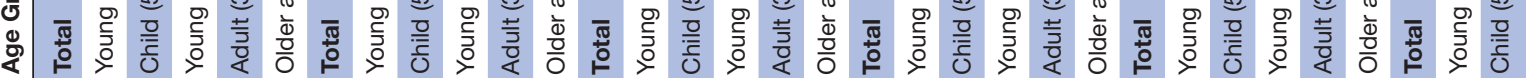
己े 


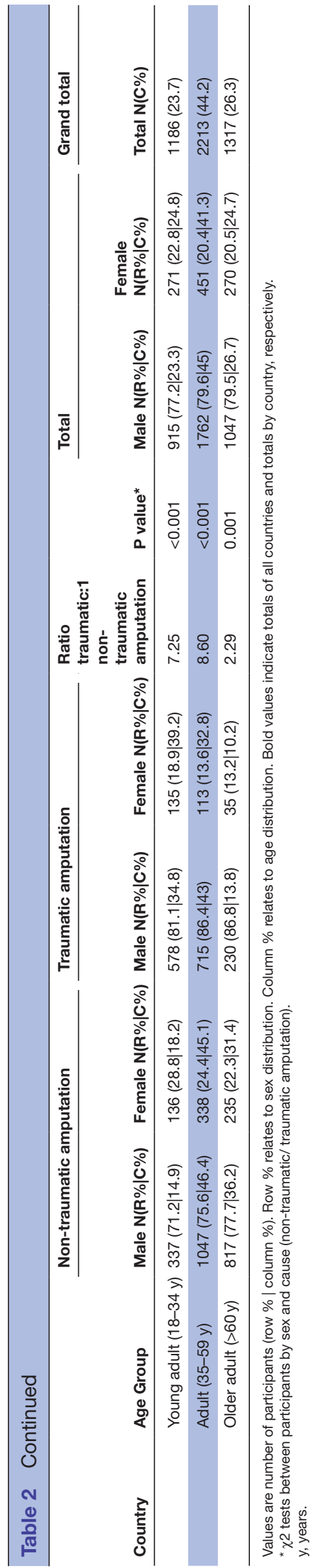

The later age observed for non-traumatic amputation is not surprising, but the average age of 48.2 years is very low compared with studies in HIC reporting ages of over $65 .{ }^{145}$ Amputations at young age as a complication of underlying health conditions such as T2D reflect the many health system challenges in the studied countries. ${ }^{46}$ Although this group attends rehabilitation significantly faster than the traumatic group, the delay is still considerable and potentially harmful in view of the risks associated with immobility in poorly managed T2D. The difference in delay between the traumatic and non-traumatic cohorts may be explained by the widespread lack of essential healthcare services during past conflict (eg, Cambodia). ${ }^{47}$ This may have led to high mortality rates in persons with conditions like T2D. PwA of traumatic origin may have survived long enough to eventually attend rehabilitation, after years of unavailability or inaccessibility of services, a possible explanation for the considerable backlog of persons with traumatic amputations. A steadfast interpretation of detailed delays is impossible owing to the extremely complex conflict history and uncertain service provision in the studied contexts including displaced populations, persons of a specific ethnicity or with a political or military past unable to cross certain combat zones. What we know for sure is that an amputation at working age and delayed prosthetic fitting and rehabilitation-not counting the unknown numbers of non-attendees-feed into the vicious cycle of disability and poverty, increasing the difficulties PwA face when it comes to reintegrating into society in these contexts. ${ }^{44} 48$

The proportions of non-traumatic and traumatic amputations are reversed compared with non-conflict countries and disclose the human cost of protracted crises. ${ }^{45} 49$ Explosive devices as amputation cause lead to complex injuries. ${ }^{425}$ Patient outcomes depend on the availability and capacity of specialised emergency and surgical care if the effects of polytraumas are handled optimally. Subject to the extent of injury and the firearm used, amputations from GSW may also be an indicator of delayed trauma and general poor healthcare. In remote areas injured people may reach medical assistance only at a stage when the affected limb can no longer be saved. Furthermore, amputation being less time-consuming and risky than limb salvage may be indicated to assist higher numbers of people. ${ }^{50}{ }^{51}$ A person with traumatic amputation needs to cope with the sudden loss when adapting to a life with permanent disability. Rehabilitation outcomes depend on the complexity of polytraumas. The psychological consequences and post-traumatic repercussion are considerable after traumatic amputation and require specialised multidisciplinary care. ${ }^{25} 4852$

The studied countries rank among the most minecontaminated contexts worldwide. ${ }^{53}$ Survivors with amputations from weapon-contamination symbolise the long-term consequences of conflict, which may last for decades and continue producing injuries and disability long after the end of active fighting. Cambodia's almost 30 years of conflict, for instance, ended in 1998. Between 


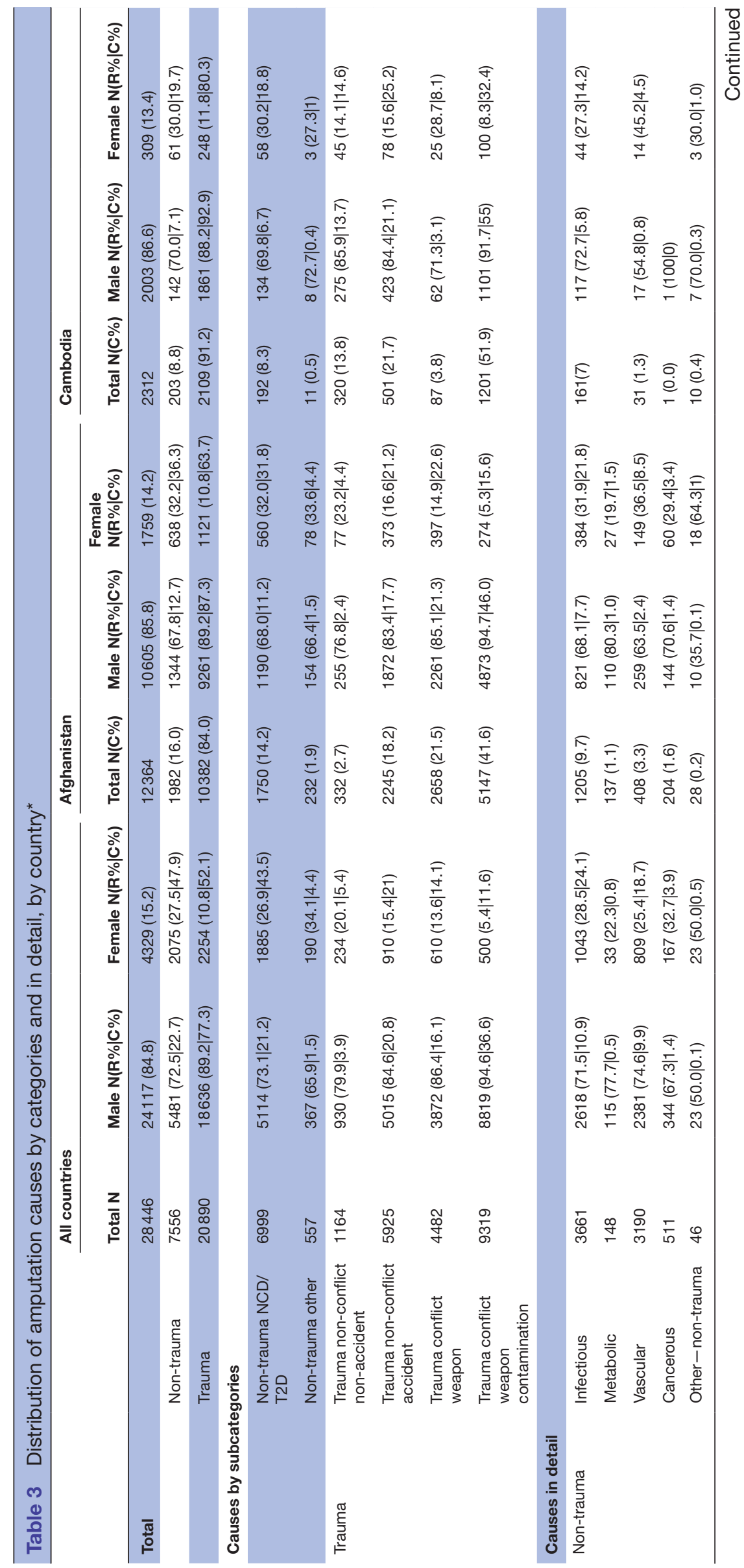

\begin{tabular}{l} 
W \\
\multirow{2}{c}{} \\
0 \\
0 \\
0 \\
\hline
\end{tabular} 


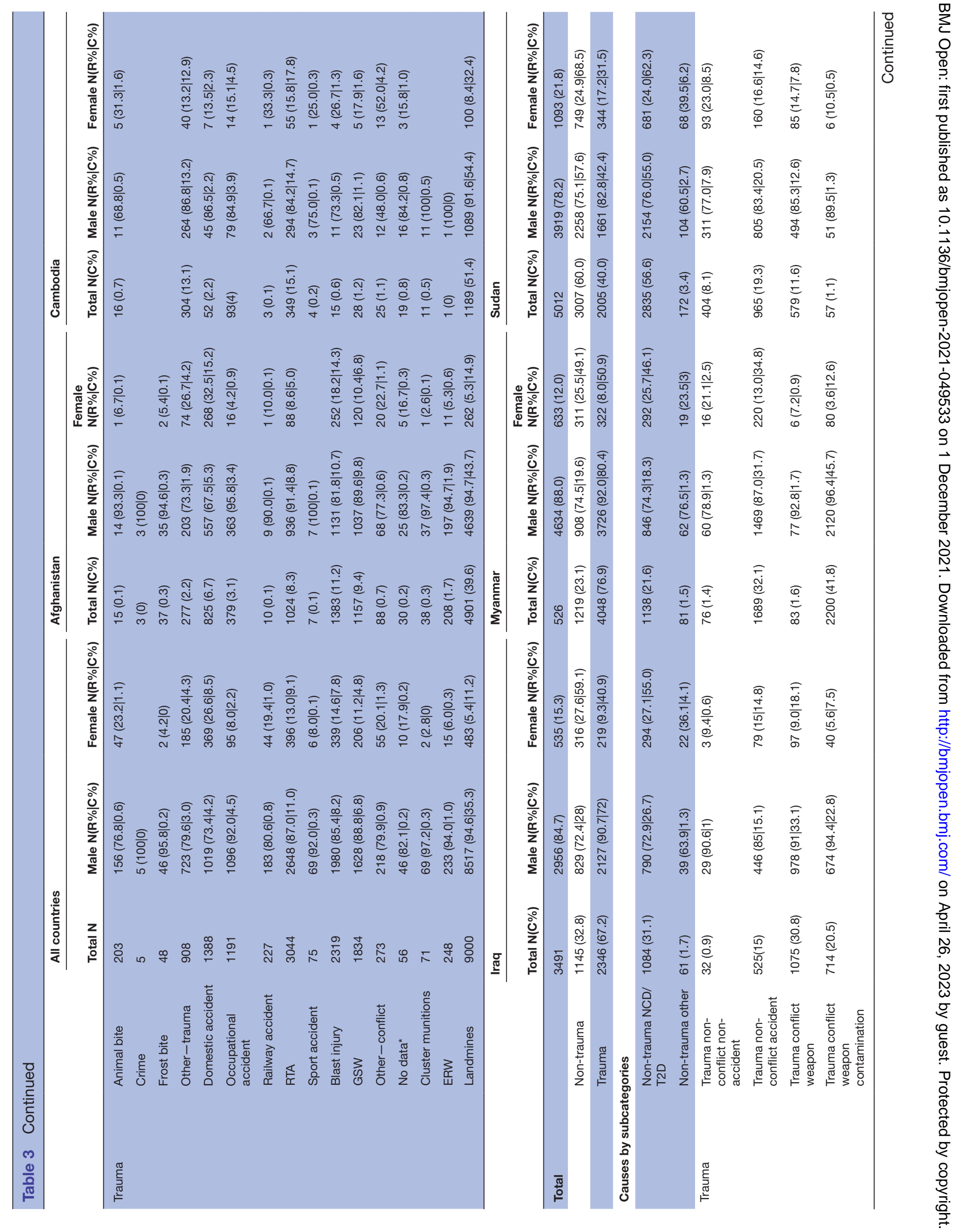




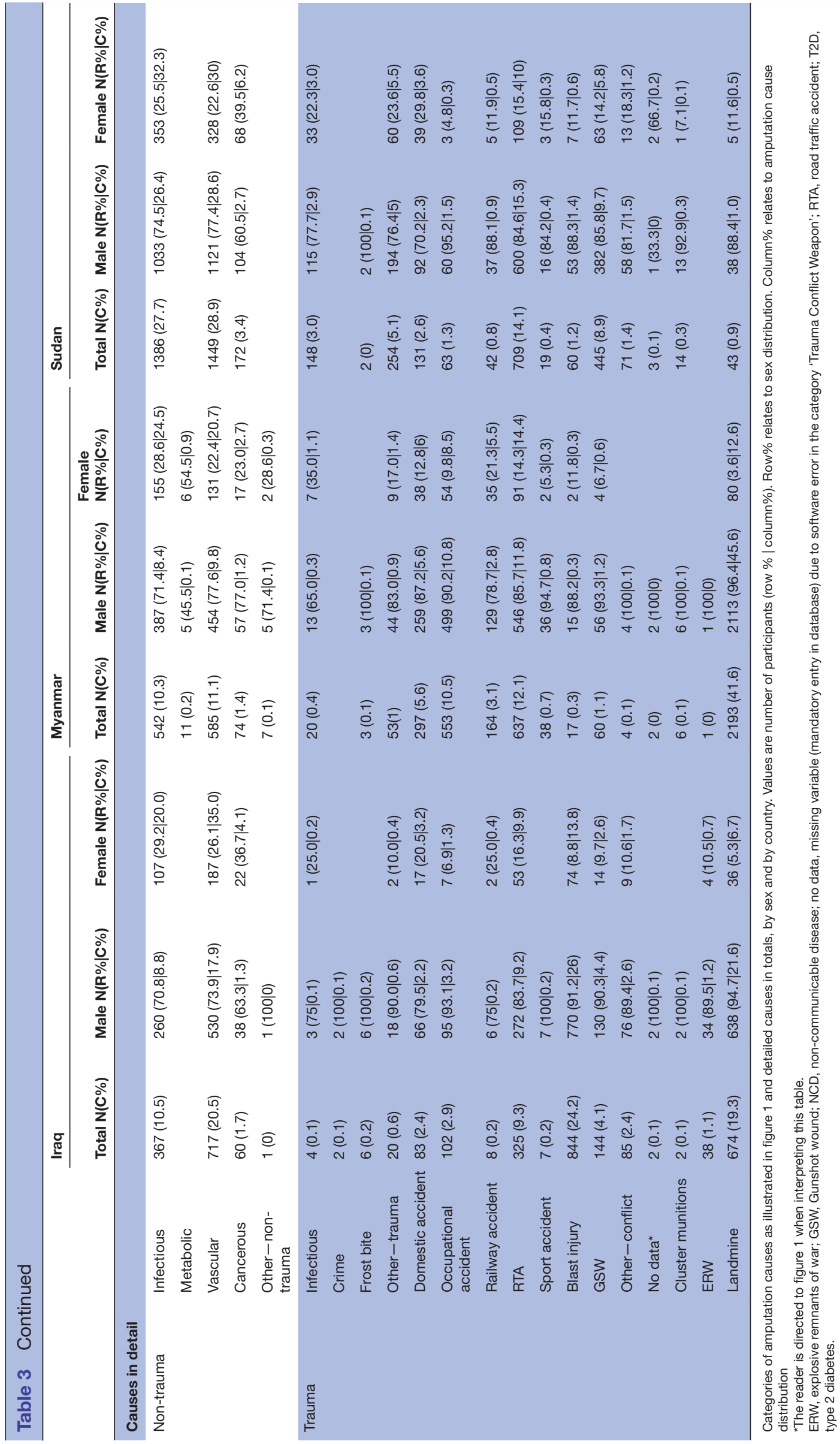




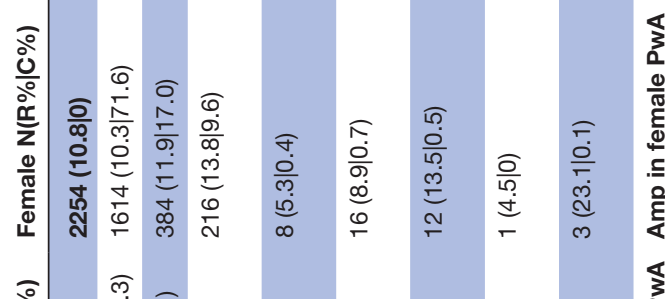

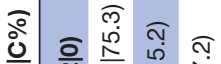

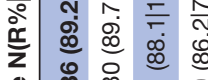

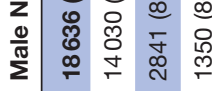

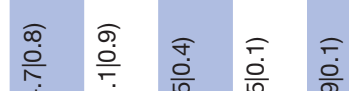
$\frac{2}{9}$ $\frac{1}{0}$
$\frac{1}{9}$ ล

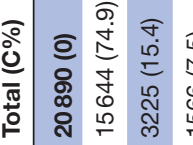
ฮู่

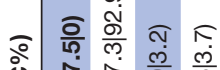

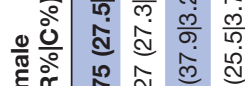

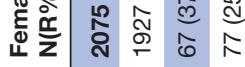

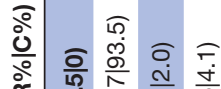

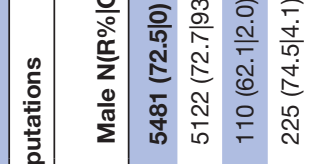

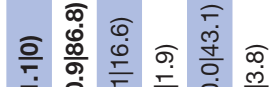

एं

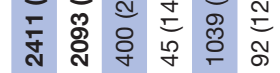

这

西

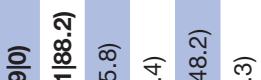

遂

पे

品

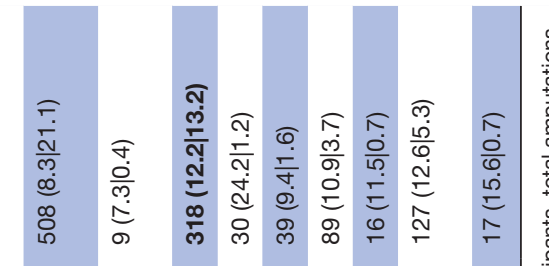

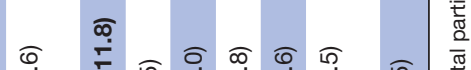

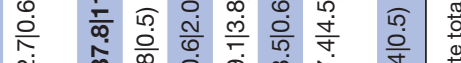

సं

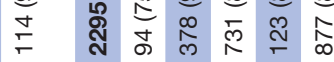

$\frac{\sqrt{9}}{3}$

กิ

要

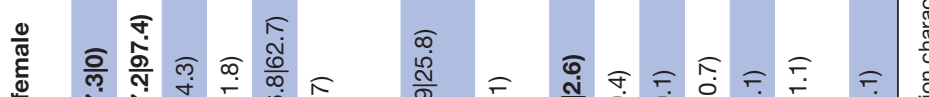
옥

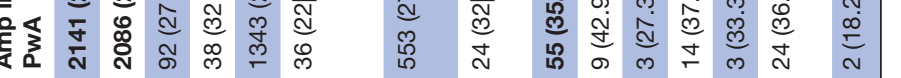

ก

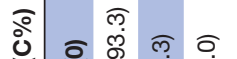

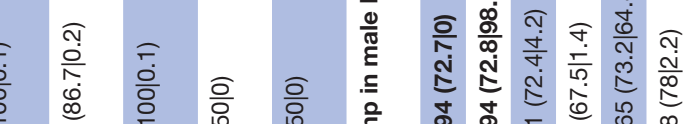

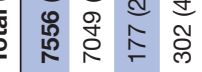

ช.

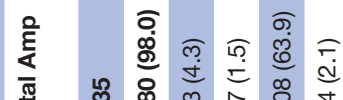

鱼 兽

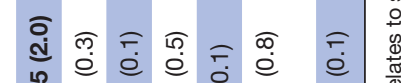

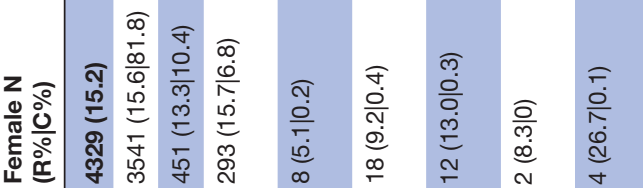

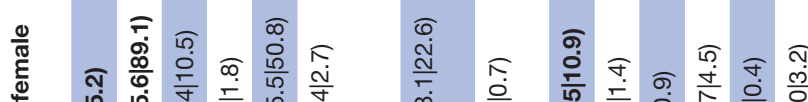

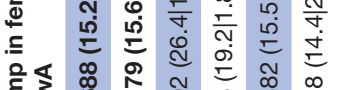
皇

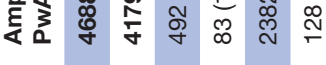

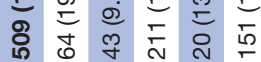

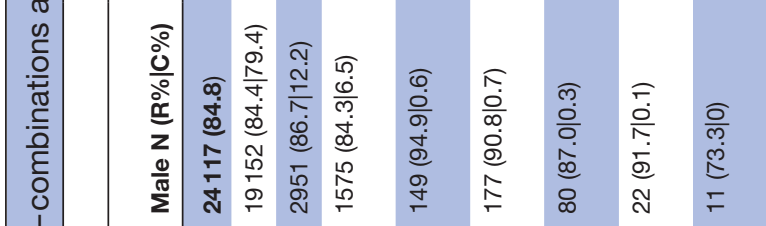

交 व

仓े

उ के

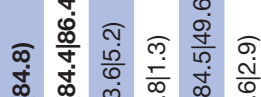

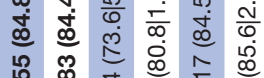

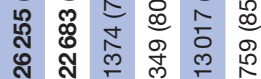

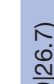

ब

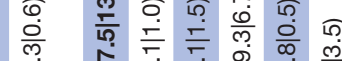

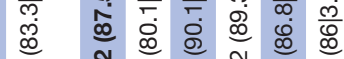

음

స్ట్ల

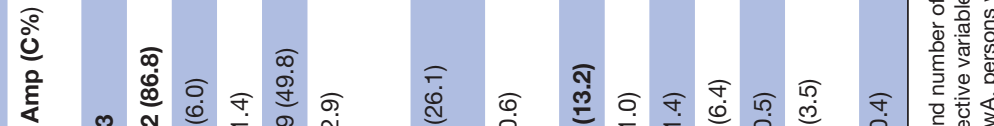

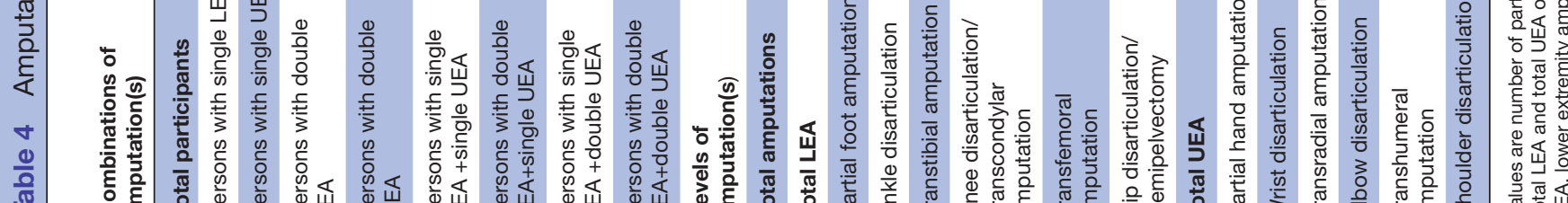

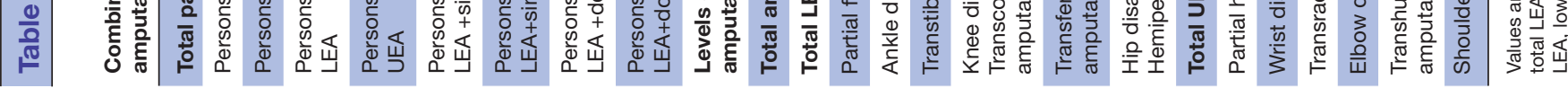


2009 and 2018, more than half of all new registrations attending rehabilitation were male PwA caused by landmines exemplifying the sustained destructive potential of conflict on a society.

Many PRCs operate independently of other health structures and without medical personnel to confirm T2D diagnosis. Therefore, the numbers of amputation due to T2D may be underestimated, a conclusion also reported in amputation incidence studies. ${ }^{1}$ Metabolic and vascular causes as noted by rehabilitation personnel without diagnostic tools and competencies were most probably linked to T2D, vascular complication of T2D or another vascular NCD. ${ }^{39}$ Likewise, most infections causing non-traumatic amputations were assumed to result from undiagnosed or undocumented T2D with infected ulcer and gangrene. ${ }^{2838}$

Common aetiologies of diabetes foot ulcer include neuropathic (approximately 55\%), arterial (10\%) and neuroischaemic causes (approximately 35\%). ${ }^{40} \mathrm{PwA}$ due to T2D in fragile settings are a highly vulnerable group. The amputation will be the consequence of a progressing chronic illness, which might be diagnosed only at the time of complication and which the person will have to cope with on top of the limb loss. If diagnosed, the person's understanding of their health status and its implications for lifestyle changes will be crucial. The risk of complications is considerable as the $39 \%-68 \%$ five years mortality rate of diabetic foot shows. ${ }^{54}$ In conflict countries, the comprehensive care required for conditions like T2D is challenged by lack of availability, affordability and access to inter-professional services for diagnosis and long-term management. It is also compromised by the environment as living in displacement and depending on aid do not facilitate the necessary lifestyle adaptations, such as diet and exercise. Deprioritisation of NCD-care in crisis settings in order to address immediate trauma and prevent epidemics puts T2D patients at higher risk of neglect. ${ }^{28}$ Regaining functionality through active rehabilitation may be more demanding compared with someone with traumatic amputation due to age and general health differences between both populations. The fitting process will be more complicated due to the remaining limb's shape and consistency. Complex chronic conditions require a kind of rehabilitation that PRCs in conflict zones may not be organised for.

The lack of T2D diagnostic data highlights the PRCs' unpreparedness for such scenarios, which will require changes of procedures, staffing ratio, occupancy rates and equipment and enhanced workforce skills regarding NCD/T2D management, diagnostics and data collections. International actors specialising in health and rehabilitation services and governments need to join forces and prioritise rehabilitation towards achieving sustainable development goal 3 which aims to 'ensure healthy lives and promote well-being for all at all ages' ${ }^{55}$ Improved NCD management on primary healthcare level is the first step. ${ }^{56}$ Equally important will be adaptations of referral systems, interprofessional collaborations across the continuum of care and investments in systematic promotion of physical activity and preventive measures for persons at risk. To implement these recommendations, the health and rehabilitation expertise of international actors should get systematically informed by the contextualised know-how and commitment of local stakeholders including governmental and non-governmental institutions, health professionals and patients.

The peak of amputation among young adult males and the significant majority of male PwA may be explained by ongoing conflict in most contexts. There is consensus in the literature that worldwide more males than females undergo amputation, but the distribution differs according to age and cause. ${ }^{15758}$ Especially during active age and regardless of conflict, rates are higher in men due to work-related or leisure-related accidents. ${ }^{49}{ }^{59}$ Despite a similar T2D prevalence among sexes, T2D-related amputation rates are higher among men due to higher prevalence of smoking, peripheral vascular disease, neuropathy and diabetic foot ulceration. ${ }^{1}$ For certain groups a gender dimension may influence access to rehabilitation. Higher female than male proportions are reported for older persons with traumatic amputations which are unlikely due to combat or occupational risk. ${ }^{58}{ }^{59}$ This is in contrast to the significant male majority in our study population. Also, our findings revealed that in urban environments, and in contrast to men, female PwA attending rehabilitation constitute a significantly larger proportion than in rural environments. Access barriers to services for women from more remote rural areas may exist such as challenging infrastructure, poverty, insecurity, and cultural factors and warrant further investigation. ${ }^{60}$

The main limitation of this study is that data is derived from ICRC PRCs only and therefore not representative of population. However, in absence of amputation incidence data this first multicountry analysis offers a unique insight into the population of rehabilitation users with amputations in fragile contexts including (ex-)combatants and civilians of all ages with amputations of all origins. As the data does not represent prevalence, but attendance to rehabilitation, it is difficult to estimate how many PwA do not receive services. Where existing, data was compared with published prevalence studies from similar contexts. The dearth of quality publications in such contexts underlines the mismatch between existing research and where the burden of disease is. ${ }^{26}$

\section{CONCLUSION}

In conclusion, this study highlights the persisting burden of amputation in conflict contexts and the consequences of broken health systems and a fragmented continuum of care. Young age and long delays to rehabilitation reveal the hardship in which PwA live in such settings. The figures of landmine-caused amputations disclose the cruel long-term dimension of conflict.

Rehabilitation services are seriously under-resourced as revealed in a recent publication on global estimates of rehabilitation needs. ${ }^{61}$ Our data have been collected in 
highly challenging and diverse settings where even basic healthcare is compromised. Providing rehabilitation and collecting data in these underserved, volatile contexts is exceptionally complex. ${ }^{30}$ The few PRCs in conflict settings cater for amputations of various causes and PwA of different age, sex, other trauma and comorbidities including psychological after-effects and future prospects of life with amputation. This requires tailored approaches matched with outcome and impact measurements. Managing these highly diverse processes is the responsibility of a multidisciplinary rehabilitation team including peer-support by other PwA-an enormous challenge in settings with so many needs and so little resources.

Preventive measures on all levels of healthcare are essential to reduce the number of T2D-caused amputations. ${ }^{62}{ }^{63}$ Rather than solely managing amputations as the last consequence, rehabilitation professionals should get increasingly involved in provision of comprehensive care.

We call out to rehabilitation service providers and healthcare professionals for a prioritisation of rehabilitation in fragile settings and a stronger and prompt involvement of rehabilitation professionals on all levels of the continuum of care. This includes international humanitarian interventions as well as local health system strengthening interventions. In addition, it is crucial that future research identifies and tests efficient, innovative, contextadapted best practice models including service provision and impact measurement to address the mismatch of rehabilitation needs and resources in fragile settings.

\section{Author affiliations}

${ }^{1}$ School of Public Health, Physiotherapy and Sports Science, University College Dublin, Dublin, Ireland

${ }^{2}$ Cochrane Switzerland, Centre for Primary Care and Public Health (Unisanté), University of Lausanne, Lausanne, Switzerland

${ }^{3}$ Department of Biomedical and Clinical Sciences (BKV), Linköping University, Linköping, Sweden

${ }^{4}$ BARC Hospital, WHO collaborating centre for research in surgical needs in LMICs, Mumbai, India

${ }^{5}$ School of Health Systems Studies, Tata Institute of Social Sciences, Deonar, India ${ }^{6}$ Health Unit, International Committee of the Red Cross, Geneva, Switzerland ${ }^{7}$ Division of Tropical and Humanitarian Medicine, Geneva University Hospitals, Geneva, Switzerland

Correction notice This article has been corrected since it was published. The name of author Sigiriya Aebischer Perone has been corrected.

Twitter Cornelia Anne Barth @neltexts and Cliona 0'Sullivan @MyCliona

Acknowledgements We would like to thank the ICRC personnel and PRC managers in the respective countries for advice and insights in data interpretation: Alberto Cairo and team from Afghanistan, Denver Graham, Phalla Keo and team from Cambodia, Therese Powell, Srood Suad Nafie and team from Iraq, Imad Aldibee and team from Sudan.

Contributors All six authors contributed to planning, conduct and reporting of the study. Specific additional contributions are as follows: CAB: literature research, data acquisition and analysis, conception and design, data interpretation, responsible for the overall content as guarantor. AW: conception and design, data interpretation. CB: conception and design, data analysis and interpretation. SAP: literature research, data interpretation. PB: data tabulation, analysis and interpretation. CO'S: literature research, conception and design, data interpretation.

Funding ICRC and Linköping University sponsored research group meetings for study design and data analysis at University College Dublin. This work was supported by the Swedish Research Council grant number 2020-03550.
Competing interests None declared.

Patient and public involvement Patients and/or the public were involved in the design, or conduct, or reporting, or dissemination plans of this research. Refer to the Methods section for further details.

Patient consent for publication Not applicable.

Ethics approval Ethical exemption to conduct analysis on deidentified data was granted by the Swiss Ethics Committee Geneva (Reference number: REQ2019-00027). Data sharing agreements between the ICRC, Linköping University and University College Dublin were approved by each institution.

Provenance and peer review Not commissioned; externally peer reviewed.

Data availability statement All relevant data are included in the tables of this study. Due to the sensitive nature of this data, data sharing is subject to regulations of ICRC data protection policy.

Open access This is an open access article distributed in accordance with the Creative Commons Attribution Non Commercial (CC BY-NC 4.0) license, which permits others to distribute, remix, adapt, build upon this work non-commercially, and license their derivative works on different terms, provided the original work is properly cited, appropriate credit is given, any changes made indicated, and the use is non-commercial. See: http://creativecommons.org/licenses/by-nc/4.0/.

\section{ORCID iDs}

Cornelia Anne Barth http://orcid.org/0000-0002-3914-6088

Cliona 0'Sullivan http://orcid.org/0000-0002-6054-4654

\section{REFERENCES}

1 Narres M, Kvitkina T, Claessen $\mathrm{H}$, et al. Incidence of lower extremity amputations in the diabetic compared with the non-diabetic population: a systematic review. PLoS One 2017;12:e0182081.

2 Unwin N. Epidemiology of lower extremity amputation in centres in Europe, North America and East Asia. Br J Surg 2000;87:328-37.

3 Wachtel MS. Family poverty accounts for differences in lowerextremity amputation rates of minorities 50 years old or more with diabetes. J Natl Med Assoc 2005;97:334-8.

4 Mathieu L, Marty A, Ramaki A, et al. Current issues with lower extremity amputations in a country at war: experience from the National military hospital of Kabul. Eur J Trauma Emerg Surg 2014;40:387-93.

5 World Health Assembly. World health assembly resolution 71.8. improving access to assistive technology 2018.

6 von Kaeppler EP, Hetherington A, Donnelley CA, et al. Impact of prostheses on quality of life and functional status of Transfemoral amputees in Tanzania. Afr J Disabil 2021;10:839.

7 MacLachlan M, Banes D, Bell D, et al. Assistive technology policy: a position paper from the first global research, innovation, and education on assistive technology (great) Summit. Disabil Rehabil Assist Technol 2018;13:454-66.

8 International Committee of the Red Cross. Prosthetic gait analysis for physiotherapists. Geneva: International Committee of the Red Cross, 2014.

9 World Health Assembly. World health assembly resolution 74. 8.The highest attainable standard of health for persons with disabilities 2021.

10 McPherson A, Durham J, Richards N, et al. Strengthening health information systems for disability-related rehabilitation in LMICs. Health Policy Plan 2017;32:384-94.

11 Nugraha B, Setyono GR, Defi IR, et al. Strengthening rehabilitation services in Indonesia: a brief situation analysis. J Rehabil Med 2018;50:377-84.

12 Borg J, Lindström A, Larsson S. Assistive technology in developing countries: a review from the perspective of the convention on the rights of persons with disabilities. Prosthet Orthot Int 2011;35:20-9

13 Skempes D, Stucki G, Bickenbach J. Health-Related rehabilitation and human rights: analyzing states' obligations under the United nations convention on the rights of persons with disabilities. Arch Phys Med Rehabil 2015;96:163-73.

14 Skempes D, Bickenbach J. Strengthening rehabilitation for people with disabilities: a human rights approach as the essential next step to accelerating global progress. Am J Phys Med Rehabil 2015;94:823-8.

15 Toro-Hernández ML, Kankipati P, Goldberg M, et al. Appropriate assistive technology for developing countries. Phys Med Rehabil Clin N Am 2019;30:847-65. 
16 World Health Organization. Emergency medical teams: minimum technical standards and recommendations for rehabilitation, 2016. Available: https://apps.who.int/iris/handle/10665/252809 [Accessed $10 \mathrm{Jul} 2019]$

17 Lathia C, Skelton P, Clift Z, et al. Early rehabilitation in conflicts and disasters, 2020. Available: https://hi.org/sn_uploads/document/ 36199-Humanity-Inclusion-Clinical-Handbook-web_1.pdf [Accessed 23 Jun 2021]

18 World Health Organization. Access to rehabilitation in primary health care: an ongoing challenge. Tech Ser Prim Heal Care 2018:1-27.

19 World Health Organization. WHO standards for prosthetics and orthotics, 2017. Available: http://apps.who.int/bookorders.\%0Ahttp:// apps.who.int/iris/bitstream/10665/259209/1/9789241512480-part1eng.pdf?ua $=1$

20 World Health Organization. Rehabilitation 2030: a call for action. The need to scale up rehabilitation; 2017.

21 Humanity \& Inclusion; Global Rehabilitation Alliance. Rehabilitation for the realisation of human rights and inclusive development; 2019.

22 Krueger CA, Wenke JC, Ficke JR. Ten years at war: comprehensive analysis of amputation trends. J Trauma Acute Care Surg 2012;73:S438-44.

23 Christensen J, Ipsen T, Doherty P, et al. Physical and social factors determining quality of life for veterans with lower-limb amputation(s): a systematic review. Disabil Rehabil 2016;38:2345-53.

24 Dougherty PJ, McFarland LV, Smith DG, et al. Combat-incurred bilateral Transfemoral limb loss: a comparison of the Vietnam war to the wars in Afghanistan and Iraq. J Trauma Acute Care Surg 2012;73:1590-5.

25 Ebrahimzadeh MH, Moradi A, Khorasani MR, et al. Long-Term clinical outcomes of war-related bilateral lower extremities amputations. Injury 2015;46:275-81.

26 Jain RP, Meteke S, Gaffey MF. Delivering trauma and rehabilitation interventions to women and children in conflict settings: a systematic review. BMJ Glob Heal 1980;2020:5.

27 James SL, Abate D, Abate KH, et al. Global, regional, and national incidence, prevalence, and years lived with disability for 354 diseases and injuries for 195 countries and territories, 1990-2017: a systematic analysis for the global burden of disease study 2017. Lancet 2018;392:1789-858.

28 Aziz ARA, Alsabek MB. Diabetic foot and disaster; risk factors for amputation during the Syrian crisis. J Diabetes Complications 2020;34:107493.

29 World Health Organization. Global status report on road safety 2018. Geneva World Health Organisation; 2018.

30 Barth CA, Wladis A, Blake C, et al. Users of rehabilitation services in 14 countries and territories affected by conflict, 1988-2018. Bull World Health Organ 2020;98:599-614.

31 International Committee of the Red Cross. Physical rehabilitation programme. annual report 2019; 2020.

32 International Committee of the Red Cross. The ICRC's mission statement, 2008. Available: https://www.icrc.org/en/doc/resources/ documents/misc/icrc-mission-190608.htm

33 International Committee of the Red Cross. Protracted conflict and humanitarian action: some recent ICRC experiences, 2016. Available: https://www.icrc.org/sites/default/files/document/file_list/protracted_ conflict and_humanitarian_action_icrc_report_Ir_29.08.16.pdf [Accessed $10 \mathrm{Jul}$ 2019].

34 The World Bank. World bank country and lending groups, 2021. Available: https://datahelpdesk.worldbank.org/knowledgebase/ articles/906519-world-bank-country-and-lending-groups [Accessed 18 Jun 2021]

35 United Nations Development Programme. Human development reports. Available: http://hdr.undp.org/en/countries [Accessed 21 Jun 2021]

36 World Health Organization. Countries. Available: https://www.who. int/data/gho/data/countries [Accessed 21 Jun 2021]

37 International Committee of the Red Cross. What is the ICRC doing to reduce the effects of weapon contamination? 2017. Available: https://www.icrc.org/en/document/overview-mine-action [Accessed 21 Jun 2020].

38 Apelqvist J, Larsson J. What is the most effective way to reduce incidence of amputation in the diabetic foot? Diabetes Metab Res Rev 2000;16 Suppl 1:S75-83.

39 Ndip A, Jude EB. Emerging evidence for neuroischemic diabetic foot ulcers: model of care and how to adapt practice. Int J Low Extrem Wounds 2009;8:82-94.
40 Wang A, Lv G, Cheng X, et al. Guidelines on multidisciplinary approaches for the prevention and management of diabetic foot disease (2020 edition). Burn Trauma 2020;8:17

41 Stevens GA, Alkema L, Black RE, et al. Guidelines for accurate and transparent health estimates reporting: the gather statement. Lancet 2016;388:e19-23.

42 Webster JB. Lower limb amputation care across the active duty military and veteran populations. Phys Med Rehabil Clin N Am 2019;30:89-109.

43 Shaw J, Challa S, Conway D, et al. Quality of life and complications in lower limb amputees in Tanzania: results from a pilot study. Lancet Glob Health 2018;6:S18.

44 Andregård E, Magnusson L. Experiences of attitudes in Sierra Leone from the perspective of people with poliomyelitis and amputations using orthotics and prosthetics. Disabil Rehabil 2017;39:2619-25.

45 Godlwana L, Nadasan T, Puckree T. Global Trends in Incidence of Lower Limb Amputation : A review of the literature. SA J Physiother 2008;64:1-5.

46 Carinci F, Massi Benedetti M, Klazinga NS, et al. Lower extremity amputation rates in people with diabetes as an indicator of health systems performance. A critical appraisal of the data collection 2000-2011 by the organization for economic cooperation and development (OECD). Acta Diabetol 2016;53:825-32.

47 Santini H. Rebirth of the health-care system in Cambodia. Lancet 2002;360 Suppl:s57-8.

48 Ferguson AD, Richie BS, Gomez MJ. Psychological factors after traumatic amputation in landmine survivors: the bridge between physical healing and full recovery. Disabil Rehabil 2004;26:931-8.

49 Heikkinen M, Saarinen J, Suominen VP, et al. Lower limb amputations: differences between the genders and long-term survival. Prosthet Orthot Int 2007;31:277-86.

50 Giannou C, Baldan M, Molde A. War surgery: working with limited resources in armed conflict and other situations of violence (volume 2). Geneva; 2013.

51 Muhrbeck M, Holmgren K, Osman Z, et al. Trends in demographics and surgical treatment of Weapon-Related limb injuries over two decades in a Resource-Scarce setting. World J Surg 2019;43:2681-8

52 Muzaffar N, Mansoor I, Hafeez A, et al. Psychiatric comorbidity in amputees with average sociodemographic status and the role of theologic and family support in a conflict zone. Australas J Disaster Trauma Stud 2012:2012:31-8.

53 Landmine Monitor. International Campaign to Ban Landmines Cluster Munition Coalition (ICBL-CMC), 2020. Available: http://www. the-monitor.org/en-gb/reports/2020/landmine-monitor-2020.aspx

54 Dietrich I, Braga GA, de Melo FG, et al. The diabetic foot as a proxy for cardiovascular events and mortality review. Curr Atheroscler Rep 2017:19:44

55 United Nations. Goal 3 | department of economic and social Affairs | sustainable Developmet | targets and indicators, 2015. Available: https://sdgs.un.org/goals/goal3 [Accessed June 14, 2021].

56 Tesema AG, Ajisegiri WS, Abimbola S, et al. How well are noncommunicable disease services being integrated into primary health care in Africa: A review of progress against World Health Organization's African regional targets. PLoS One 2020;15:e0240984.

57 Ephraim PL, Dillingham TR, Sector M, et al. Epidemiology of limb loss and congenital limb deficiency: a review of the literature. Arch Phys Med Rehabil 2003;84:747-61.

58 Varma P, Stineman MG, Dillingham TR. Epidemiology of limb loss. Phys Med Rehabil Clin N Am 2014;25:1-8.

59 Dillingham TR, Pezzin LE, MacKenzie EJ. Incidence, acute care length of stay, and discharge to rehabilitation of traumatic amputee patients: an epidemiologic study. Arch Phys Med Rehabil 1998;79:279-87.

60 Sen G, Östlin P. Gender inequity in health: why it exists and how we can change it. Glob Public Health 2008;3 Suppl 1:1-12.

61 Cieza A, Causey K, Kamenov K, et al. Global estimates of the need for rehabilitation based on the global burden of disease study 2019 : a systematic analysis for the global burden of disease study 2019. Lancet 2021;396:2006-17.

62 Hap K, Biernat K, Konieczny G. Patients with diabetes complicated by peripheral artery disease: the current state of knowledge on physiotherapy interventions. J Diabetes Res 2021;2021:1-12.

63 APCF F, Palma MR, Lacombe JCA. Implementation of physiotherapeutic shares in the prevention of diabetes complications in a family health strategy. Fisioter em Mov 2015;28:69-76. 